\title{
Parâmetros do sistema artístico e cultural no jornal Diário do Sul (1986-1988): a centralidade da economia na cobertura de cultura*
}

\section{RESUMO}

$\mathrm{O}$ artigo discute os parâmetros da representação do sistema artístico e cultural propostos pelo jornal Diário do Sul, periódico do grupo Gazeta Mercantil, que circulou entre 1986 e 1988 no Rio Grande do Sul. Dentre os parâmetros, destaca a centralidade da economia na cobertura de arte e cultura. Apresenta um recorte dos resultados da pesquisa Jornalismo e representação do sistema artístico-cultural nos anos 80: um estudo do Jornal Diário do Sul (Porto Alegre, 1986 - 1988), realizada com base em análise de conteúdo e técnicas de história oral.

\section{PALAVRAS-CHAVE \\ jornalismo cultural \\ Diário do Sul \\ Gazeta Mercantil}

\section{ABSTRACT}

The article discusses the parameters of the representation of the artistic and cultural system proposed by the Diário do Sul, newspaper of the group Gazeta Mercantil, which circulated between 1986 and 1988 in Rio Grande do Sul, pointing out the centrality of the economy in the covering of art and culture. It presents part of the results of the research Journalism and representation of artistic and cultural system in 80 years: a study of the newspaper Diario do Sul (Porto Alegre, 1986 - 1988), held on the basis of content analysis and techniques of oral history.

\section{KEY WORDS}

cultural journalism

Diário do Sul

Gazeta Mercantil

\section{Cida Golin}

Professora do Programa de Pós-Graduação em Comunicação e Informação da UFRGS/RS/BR

cidago@terra.com.br

\section{Ana Gruszynski}

Professora do Programa de Pós-Graduação em Comunicação e Informação da UFRGS/RS/BR

anagru@gmail.com
Análise e informação contextualizada, abordagem de revista diária com perfil cosmopolita: estas foram metas editoriais que perfizeram a ambição do jornal Diário do Sul, lançado em Porto Alegre em 04 de novembro de 1986, pelo Grupo Gazeta Mercantil. O periódico surgiu em meio ao processo de redemocratização do país, a dez dias da eleição de governadores e do Congresso Nacional Constituinte, em um cenário econômico inflacionado pela derrocada do Plano Cruzado. A proposta audaciosa resultou em 581 edições publicadas até setembro de 1988 e arrebatou 18 prêmios, entre eles o Prêmio Esso de Melhor Contribuição à Imprensa.

Com o objetivo de discutir os principais parâmetros da representação do sistema cultural propostos pelo jornal e a centralidade da economia evidenciada na cobertura de arte e cultura, o presente artigo apresenta um recorte dos resultados da pesquisa Jornalismo $e$ representação do sistema artístico-cultural nos anos 80: um estudo do jornal Diário do Sul (Porto Alegre, 1986 - 1988)1. A investigação estruturou-se a partir de análise de conteúdo ${ }^{2}$, revelando uma panorâmica quantitativa da cobertura cultural e aspectos qualitativos no trato desse tipo de informação. Por meio de técnicas da história oral ${ }^{3}$, entrevistas com 12 membros da equipe editorial permitiram, mesmo sob a distância temporal e com a reconstrução lacunar da memória, uma perspectiva sobre os processos editoriais peculiares à história desse periódico.

\section{O Diário do Sul e o Grupo Gazeta Mercantil}

A gênese do Diário do Sul (DS) encontra-se na inserção regional do jornal Gazeta Mercantil (GzM), principal diário brasileiro especializado em economia na segunda metade do século XX. Por meio de um sistema de impressão via satélite, o periódico passou a imprimir páginas nas cidades onde havia sucursais, facilitando sua distribuição no final dos anos 1970 (Lene, 2004). A Gazeta Mercantil Sul, encarte criado em julho de 1984 em Porto Alegre, produzia pautas da cidade e de âmbito estadual, e se tornou a segunda sucursal em número de assinantes, atrás somente de São Paulo4. Pela forma cuidadosa com que tratava o circuito artístico, entretenimento e gastronomia, a publicação - apelidada de Gazetinha - superou o perfil do público interessado somente em economia, singularizando o trabalho desenvolvido no estado.

A experiência bem-sucedida da GzM com seus cadernos regionais, o fechamento do tradicional diário sulino Correio do Povo em 1984 e a possibilidade de utilizar seu parque gráfico - posteriormente não efetivada - fortaleceram os argumentos para aprovação 
do projeto do novo diário por Luiz Fernando Levy, diretor e proprietário da Gazeta. O plano incluía um estudo detalhado de infra-estrutura, investimentos e custos para um período de cinco anos, prevendo também a participação de capital de empresas gaúchas. (Marini, 2002). Nos anos 1980, a Gazeta Mercantil encontrava-se ainda em ascensão como o único diário de economia de cobertura e circulação nacional, atingindo em 1987 o recorde de tiragem e receita operacional líquida. Com perfil especializado, assumia a proposta de ser o segundo jornal preferido em cada cidade onde circulasse, já que a primazia seria sempre do periódico local com notícias mais próximas à média dos leitores (Lene, 2004, p. 80).

Ao ter como modelo o espanhol El País e outros quality papers, o diretor Hélio Gama Filho selecionou um grupo inicial de jornalistas capaz de sustentar um perfil desse gênero. Vários desses profissionais haviam passado por redações de revistas e jornais nacionais, além de terem vivenciado experiências locais significativas como a Folha da Manhã e o Coojornal. Outros vieram da Gazetinha, detinham estratégias comuns relacionadas às práticas jornalísticas, e compartilhavam ideais aguçados pela imprensa local em crise e pelo contexto de redemocratização do país - de construir um jornal moderno em que a credibilidade e a ética seriam imperativos. Um seminário com especialistas de diferentes áreas permitiu à equipe inicial aprimorar o projeto, conformando o periódico.

Os quality papers são publicações reconhecidas pela qualidade de sua cobertura e edição, com artigos assinados por especialistas e estilo de texto singular. Buscam uma aproximação informativa, evitam o sensacionalismo, e frequentemente fazem referência a outras publicações de perfil similar. Distinguem-se pelo formato standard e circulam prioritariamente por assinaturas. Costumam apresentar várias matérias na capa e evitam a presença de anúncios nesse espaço. Em termos de layout, privilegiam o texto em detrimento da imagem, configurando a página de modo sóbrio e tradicional. Em linhas gerais, opõem-se aos jornais de caráter popular, identificados com o formato tablóide. (Malovic; Vilovic, 2009; Chloë, 2009; Connell, 1988) Ainda que tais características venham sendo rediscutidas na contemporaneidade, verificou-se que os elementos indicados coincidem com a proposta do Diário traçada na década de 1980.

O Manual de Redação do DS enfatizava os princípios de construção da credibilidade, seguindo rotinas editoriais semelhantes às da $\mathrm{GzM}^{5}$. As matérias deveriam, em princípio, apresentar um perfil analítico, explicitando o contexto, causas e consequências, com checagem precisa das informações. A assinatura dos textos, prática também assumida desde o início pelo DS, visava tornar o jornalista co-responsável pelo material publicado. Buscava-se em cada editoria o fortalecimento da expertise, fazendo com que os repórteres fossem conhecidos pela competência no trato de determinados assuntos (Lene, 2004). Recomendava-se um texto acessível a leitores do " $2^{\circ}$ grau ao pós-doutorado, [...] sem lugares comuns e suficientemente claro" (Manual de redação, s/d, p. 3)

Conforme Gama (2008), o Diário do Sul buscava atingir um público segmentado de classes A/B, formados na sua origem por executivos, expandindose para camadas médias de formadores de opinião, trabalhadores intelectuais, pesquisadores, leitores que dedicariam ao jornal um tempo longo de leitura. Seguindo o paradigma da GzM, o periódico nasceu com uma biblioteca e um banco de dados estruturados no centro da redação para subsidiar a construção das principais matérias (Rozados, 2009) em uma época anterior à internet. A iniciativa rara de indexar todo o jornal em um índice, publicado após seis meses de circulação, revelava a aspiração editorial, dentro de um ideal enciclopédico, de formação do leitor e de se tornar uma referência a longo prazo.

A opção por uma cobertura aberta ao mundo e não dedicada somente à cena local se intensificou por meio de acordos com várias agências e publicações internacionais. $\mathrm{O}$ jornal detinha direitos de publicação - alguns exclusivos no Brasil -, de periódicos como Business Week, Foreign Affairs, The Guardian, New York Times, Los Angeles Times, Washington Post, El País, Rolling Stone, Asahi Shimbum e Le Monde. Cadernos especiais eram editados sistematicamente recobrindo temas diversificados. A proposta era trazer todas as editorias para a capa, assegurando à cultura um lugar privilegiado. Sabia-se da importância estratégica desta editoria para a fidelidade do público-alvo, afinal o consumo cultural expressa hierarquias, hábitos e distinções sociais e cresce conforme o aumento do nível sócio-cultural.

Ao longo de dois anos de existência, dificuldades financeiras comprometeram a continuidade do projeto. Segundo Rüdiger (2003), o jornal do grupo Gazeta Mercantil tentou suprir o hiato deixado pela tradição cultural do antigo Correio do Povo, mas foi derrotado pela estratégia mercadológica do conglomerado de mídias da Rede Brasil Sul - RBS e pelo próprio retorno do Correio, com novos proprietários, em formato tablóide. Para Fonseca (2008), há duas fases na trajetória das empresas de comunicação gaúchas: a empresarial que se estende até o final da década de 1970, representada pelo Correio do Povo, e que corresponde à etapa concorrencial do capitalismo retardatário brasileiro; e a das indústrias culturais que, a partir da década de 1980, consolida a hegemonia da RBS dentro da etapa monopólica do capitalismo ${ }^{6}$. Neste perfil de negócio, as empresas buscam adotar estratégias de domínio do mercado que evitem o surgimento de uma efetiva concorrência.

Por outro lado, apesar do êxito do encarte regional da GzM, demonstrando que havia público e mercado 
próprio para o caráter segmentado da publicação, o projeto autônomo do Diário do Sul não teve aprovação unânime no âmbito empresarial do grupo Gazeta Mercantil. Embora apoiado por Levy, que assegurou o investimento inicial para que o jornal gradualmente se auto-sustentasse, "o pessoal do editorial da Gazeta via o jornal como um desvio, como uma divisão de opinião" (Gama, 2008) ${ }^{7}$. Segundo Gama (2008), essa dissensão marcou o percurso do Diário em embates de diferentes ordens, desde questões logísticas de impressão a 155 quilômetros de Porto Alegre, passando pelo fatal e sistemático atraso de salários a partir de 1987. Esses são alguns dos fatores que determinaram o fechamento do Diário do Sul em 30 de setembro de 1988, reforçado pelo difícil mercado jornalístico sulino no período dominado pelo grupo RBS. Em dois anos, o DS passou da tiragem inicial de 10 mil exemplares para 39.700 exemplares na última edição de 26 páginas ${ }^{8}$.

\section{0 jornalismo e o tratamento da cultura no jornal Diário do Sul}

A dinâmica de relações entre instituições, agentes, produtos, processos e produção de valor configura o sistema cultural no qual o jornalismo cumpre uma função mediadora. Por meio de suas estratégias discursivas e das escolhas editoriais, dinamiza, documenta e avaliza, contribuindo na formação de públicos e na construção de parâmetros interpretativos para avaliar a cultura de um determinado período e local.

Na periódica revisão de temas artísticos e culturais, assim como na apresentação de novas tendências, o jornalismo alicerça e constrói a memória simbólica, confirmando sua condição de práxis narrativa marcada pela cultura profissional e pelo contexto em que está inserida. Assim, participa do mecanismo de criação de consensos sobre o que significa a cultura de uma época, consenso esse formado dentro do próprio sistema cultural. O discurso jornalístico apropria-se de valores intrínsecos a esse universo, tais como o cânone, a tradição e a respeitabilidade dos pares, além dos critérios mercadológicos.

Ao atuar como um filtro, o jornalista produz perspectivas e abordagens parciais sobre o sistema cultural, priorizando muitas vezes a divulgação de produtos e relegando a um segundo plano os processos culturais. Entende-se por processos culturais as políticas públicas, a economia do setor, questões do processo artístico que antecedem ou estão para além do evento ou do produto acabado (Cunha et al., 2002).

Na primeira fase do jornal Diário do Sul, a editoria de Cultura ocupava duas páginas, seguida pelo segmento de comportamento e lazer. Imprimia-se ali o conceito erudito de cultura ao separar manifestações artísticas (música, artes, cinema, literatura, dança, teatro) do entretenimento (televisão, rádio, moda, esportes, xadrez, quadrinhos e horóscopo). A criação da editoria de Imagem em julho de 1987 deslocou o cinema para perto do vídeo e da TV. Por fim, em 1988, a Cultura encontrava-se agrupada com Lazer e Comportamento em um caderno separado, seguindo a tendência dos diários nacionais.

Um panorama do sistema cultural pode ser visualizado por meio da quantificação de seis meses alternados do jornal, conforme dados publicados $(2008)^{9}$. Este levantamento foi corroborado pela amostra qualitativa (seis semanas, uma de cada mês) ${ }^{10}$, momento em que se percebeu o diálogo entre a ambição cosmopolita do periódico e o critério jornalístico da proximidade. Porto Alegre constitui o local predominante da cobertura $(47 \%)$, perdendo para a soma das referências regionais (19\%), nacional (19\%) e internacional (15\%). Pondera-se, nessa perspectiva, que a contribuição principal do Diário do Sul foi mesmo o registro minucioso das especificidades do sistema de cultura local, confirmando o que disse o primeiro editor da área, Carlos Urbim (2009): “a pedra angular da cobertura era visualizar o cenário local com uma lupa, mas ter um periscópio em cada fuso horário". Sob a relatividade de uma amostra, a quantificação dos segmentos culturais demonstrou que o cinema (18\%) era o tema predominante, seguido por música $(15 \%)$, literatura $(12 \%)$, agenda cultural $(12 \%)$, artes plásticas $(9 \%)$, teatro ( $8 \%$ ) e televisão $(6 \%)$. Todos são segmentos-chave na esfera do jornalismo cultural que segue o sentido mais usual do termo cultura, ou seja, o das artes e do trabalho intelectual (William, 2000).

Como já escreveu Tubau (1982), a cultura apreendida por meio do discurso jornalístico é somente aquela capaz de se tornar notícia. A partir das análises realizadas, concluiu-se que os parâmetros de representação do sistema cultural no jornal Diário do Sul seguiram critérios usuais de noticiabilidade, como atualidade, proximidade, relevância e notoriedade dos sujeitos envolvidos. As fontes explicitadas nas notícias e reportagens foram os agentes do circuito (artistas, produtores, dirigentes, empresários, intelectuais, críticos ou publicações da área), com especial acento nos criadores. Nesse aspecto, a narrativa jornalística mimetiza a própria lógica da economia da cultura, ao enfatizar o criador, amplificar a singularidade e a personalização como elementos vitais para formação do valor do bem cultural, seja ele único ou múltiplo (Benhamou, 2007; Tolila, 2007).

Detectou-se também a linguagem de antecipação característica do jornalismo cultural que representa o sistema como uma sequência linear de eventos, embora seja marcante a iniciativa do jornal em situar o fato sob perspectiva histórica, recorrendo à memória. Parte-se do tempo presente e a narrativa oscila entre o passado e o futuro (prospecção). O jornal enfatizou a cultura elitizada, referendou o consenso e o cânone estabelecidos no próprio campo, ainda que na prática abrisse eventuais brechas na cobertura de 
manifestações de teor experimental ou underground.

$\mathrm{O}$ realce dado ao serviço, privilegiando roteiros de programação, e tendo como parâmetro o consumo do leitor da classe média urbana, foi uma das apostas dos jornais a partir dos anos 1980 (Januário, 2005). O DS não fugiu deste perfil pragmático, sobretudo no caderno Cultura e Lazer, quando ocorre a junção das agendas de diversas áreas. Junto à proposta formativa do leitor, evidenciada no tratamento contextualizado da informação, as páginas de cultura foram guias para o tempo livre, valorizando o consumo e o produto.

\section{A economia na cobertura de cultura}

Em contraponto à ênfase no produto final, que predomina nas narrativas jornalísticas da área refletindo o movimento de oferta típico da economia da cultura, nota-se a tentativa do DS em pautar os processos culturais. Herdeiro dos preceitos da GzM, o periódico deu especial atenção à economia do campo cultural. A amostra qualitativa revela uma perspectiva deste enfoque que atravessa, em maior ou menor grau, todos os segmentos abordados. O periódico observou aspectos como preço, construção do valor do bem cultural, custos de produção, geração de emprego e renda no setor, consumo individual de cultura, investimentos no espaço urbano e a relação entre o estado e a iniciativa privada nesse segmento.

Com base na amostra qualitativa, destacaremos agora detalhes deste trabalho jornalístico que iluminou o cenário porto-alegrense por meio do entendimento da cultura como economia e negócio. Porto Alegre, na década de 1980, era o terceiro pólo nacional de artes plásticas e consolidava o sistema de arte e o mercado local (Brittes, 2008). A amostra revela um circuito expressivo de galerias de perfis distintos, desde as estabelecidas a partir de nomes consagrados e de circulação nacional (como exemplos, galerias Tina Presser e Bolsa de Arte) até aquelas que correram na faixa de risco do mercado ao apostar em artistas da geração 80 (Arte\&Fato), ou mesmo se especializando em determinadas linguagens como o tridimensional (Singular). Um relatório especial do jornal confirma que o investimento em arte foi uma das modalidades mais lucrativas do Plano Cruzado, com uma valorização de quase $200 \%$, abarcando um novo contingente de público formado pela classe média ${ }^{11}$.

Há pelo menos três gerações artísticas em atividade no período e, por meio da programação diversificada, as notícias analíticas situam a trajetória de criação do artista jovem ao consagrado e sua cotação no mercado. Em geral, esta referência aparece logo no lead, confirmando o quanto o valor da obra era uma informação prioritária para o jornal. Como relembra o repórter e editor Luiz Carlos Barbosa:

[...] havia uma fatia desses leitores que comprava a obra de arte, talvez não por um sentido estético mais apurado, mas porque aquilo era um ativo financeiro interessante. E a gente tinha uma seriedade nisso, quer dizer, uma obra que fosse 100 dólares tu não dizias que era 1000 dólares. Esse público era um público que tu influenciavas na hora da compra. Se tu dizias assim: um artista emergente..., mostrando isso através da matéria, ou ouvindo um crítico de arte, ou descrevendo, acho que isso influenciava na compra. E as galerias sabiam disso, elas nos assediavam, os próprios artistas nos assediavam (Barbosa, 2008).

Em um mercado caracterizado pela incerteza, os intermediários assumem um papel decisivo. O consumidor é sensível ao valor da informação, às considerações especulativas, buscando elementos para interpretar e avaliar a qualidade dos produtos. (Tolila, 2007; Benhamou, 2007). Pelos valores registrados, percebe-se que a cobertura de artes do DS é exaustiva, mapeando inclusive os espaços alternativos. Em novembro de 1986, preços de artistas gaúchos na faixa dos 40 anos, como Magliani e H. Fuhro, subiram cerca de $600 \%$ no ano, enquanto consagrados como Iberê Camargo ou Ado Malagoli valorizaram mais de 300\%, com saída imediata nas galerias.

O circuito teatral de Porto Alegre também é construído por meio da sondagem de dados econômicos. Entre 1986 e 1988, o roteiro do DS registra a movimentação de 14 teatros. É possível visualizar uma diversidade de grupos e diretores atuantes na cena local. A cobertura possibilita uma aproximação dos bastidores, delineando o custo das produções ou mesmo o impacto da crise econômica na linguagem teatral. Um fragmento da abertura da reportagem abaixo, por exemplo, contextualiza um período em que as fórmulas televisivas são as soluções mais fáceis encontradas para driblar uma conjuntura inflacionada que impede as raras pesquisas de linguagem e a manutenção de um elenco ensaiando por um longo período:

[...] economia e linguagem teatral estão imbricadas dentro de uma relação orgânica, que inclui não apenas pressão econômica sobre a criação artística, mas também formação intelectual e agudeza para responder ou não às adversidades. [...] Interpretação, linguagem e encenação, assuntos na pauta do Encontro Renner de Teatro, consumiram boas horas de debate e uma conclusão melancólica. Não dá mais para negar que existe uma crise da teatralidade no Brasil. Algo que começa na dramaturgia, passa pelas formas de interpretação e alcança a encenação, que cristaliza o domínio da linguagem televisiva no palco $^{12}$.

Segundo levantamento da reportagem ${ }^{13}$, a figura do produtor executivo, na função de conciliar as necessidades e os custos de um espetáculo cênico, 
surge como estratégica na busca do patrocínio. As produções, tendo como padrão o Rio de Janeiro, oscilam entre 6 milhões de cruzados (espetáculos com até dois atores) e 50 milhões de cruzados. A peça $A$ Fonte, encenada no primeiro semestre de 1988 e que foi descrita pelo crítico Antonio Hohlfeldt como um divisor de águas, sinalizando a maturidade das artes cênicas no RS ${ }^{14}$, recebeu investimento de mais de 10 milhões de cruzados da Opus Produções. Em um momento de retração do poder aquisitivo do público, a lotação de meia casa significa parâmetro de sucesso para as peças teatrais.

O mercado editorial, por sua vez, se articula pela ação de um número significativo de editoras locais (Mercado Aberto, Tchê, Movimento, L\&PM, Kuarup) em uma economia em crise. A reportagem levanta custos e nichos de investimento como, por exemplo, a literatura infantil, segmento em forte crescimento na época, sendo responsável por uma média mensal de dois lançamentos e pela venda de $50 \%$ dos livros de ficção no País, cerca de 20 milhões de exemplares ${ }^{15}$. Durante a $32^{a}$ Feira do Livro em 1986, que vendeu mais de 400 mil livros em duas semanas, o DS encomendou uma pesquisa a uma empresa especializada a fim de sondar o perfil do consumidor desse tradicional evento editorial em Porto Alegre. Pelo menos 72\% dos entrevistados planejavam suas compras a partir de indicações de amigos, colegas e professores. A polêmica sobre a veracidade da lista dos livros mais vendidos também foi levantada pela pauta que era antecedida por pesquisa e um rigoroso planejamento prévio (Weiss, 2009).

Entre dezembro de 1986 e janeiro de 1987, livrarias como Sulina, Mercado Aberto e Edições Paulinas investiram na ampliação e em novas lojas no centro da cidade, refletindo ainda o aquecimento que o Plano Cruzado propiciou ao mercado livreiro. Mesmo após o Plano Cruzado II de novembro de 1986, que liberou os preços dos produtos e serviços fazendo a inflação disparar, as editoras gaúchas abriram o ano de 1987 com um número significativo de lançamentos. No entanto, os editores foram unânimes em alertar sobre aumentos de 50 a $80 \%$ no preço do catálogo, resultantes dos elevados custos do papel, composição e gráfica.

Em uma fase anterior aos hipermercados culturais e à implantação do multiplexos, o roteiro do DS aponta o aumento do número de cinemas em Porto Alegre entre 1986 e 1988, crescimento esse geralmente resultante da divisão de uma grande sala em duas. São 30 os cinemas em setembro de 1988, todos de rua e concentrados no centro e nos principais bairros da capital. A amostra indica a presença hegemônica da indústria hollywoodiana na programação, seguida pela produção européia e latino-americana, em especial o cinema argentino. Este circuito é acompanhado diariamente pelo crítico e editor Luiz Carlos Merten. Segundo dados do período, $70 \%$ do público regular de cinema, tanto nos EUA como no Brasil, estava na faixa etária até $25 \operatorname{anos}^{16}$. Como comprovou o relatório do DS sobre os lugares freqüentados pelos jovens gaúchos em 1986, o cinema era um dos programas favoritos, de preço acessível e para todos os gostos ${ }^{17}$.

Simis (2009) comenta quea década de1980 apresentou uma redução expressiva dos espectadores no Brasil, reflexo tanto da recessão econômica quanto do aumento do preço do ingresso na migração dos cinemas para os shoppings, assim como pela concorrência de novos formatos como o vídeo. A cobertura acompanhou de perto a popularização deste aparelho que alterou de forma radical a recepção cinematográfica. Em novembro de 1986, uma loja no centro de Porto Alegre chegava a vender 50 videocassetes por dia, os consumidores aceitavam qualquer marca e atrasos de até 20 dias na chegada do produto. O relatório especial sobre vídeo apontava o problema crônico da época: $17 \%$ das fitas que circulavam nas quatro mil locadoras brasileiras (300 delas no RS) eram piratas ${ }^{18}$. Na busca pela segmentação, o jornal passou a oferecer o suplemento semanal Espectador Vídeo, tablóide de forte apelo gráfico, especializado na área. O relançamento dos filmes em vídeo, naquele momento, privilegiou a produção norte-americana.

Depois do cinema, a música é o segmento com maior espaço nas páginas do DS. Na década de 1980, o Brasil era o sexto mercado na área da indústria fonográfica (Ortiz, 1988), segmento estruturado em torno das grandes gravadoras, do disco vinil e de uma estratégia horizontal de atuação que apostava em vários estilos, especialmente o rock (Dias, 2008). Por meio da crítica e do comentário, o jornal acompanha os lançamentos e divulga uma agenda sistemática de shows nacionais e internacionais em Porto Alegre. A capital assiste ao incremento da sua música local urbana, do rock ao regionalismo, fenômeno presente nos eventos de reabertura do auditório Araújo Vianna (janeiro de 1987) e do Salão de Atos da UFRGS (julho de 1988) ${ }^{19}$. Como demonstram essas matérias, verificase uma ação sistemática, tanto do poder público como da iniciativa privada, na renovação da infra-estrutura cultural da cidade ${ }^{20}$, e a cobertura jornalística segue interessada nos valores investidos. Na área da música erudita, faltam recursos públicos para contratar os aprovados em concurso da orquestra sinfônica estatal (OSPA). Os dados levantados explicam a evasão dos músicos eruditos para o exterior em busca de melhores mercados: um violinista ganhava em média mil dólares em 1970, salário que, pela variação inflacionária, reduziu-se para 200 dólares em julho de 1988, fora os custos mensais de manutenção do instrumento ${ }^{21}$.

\section{Uma perspectiva sobre a institucionalização da Cultura}

Além de mapear a economia do setor, o jornal registrou uma etapa histórica de institucionalização da Cultura, momento em que se desvinculou dos órgãos 
de Educação. O Ministério da Cultura foi criado em 1985, mesmo ano da criação da Secretaria Municipal de Cultura de Porto Alegre. A amostra traça um retrato da política do período, acompanhando os dois primeiros anos de Pedro Simon no governo estadual (1987-1988) e as propostas dos artistas e intelectuais para a nova administração. Um dos primeiros decretos do governo, em janeiro de 1987, separou a Cultura da Educação, deixando o Conselho de Desenvolvimento Cultural (CODEC) autônomo na gerência de 23 instituições culturais e uma ínfima verba de 25 milhões de cruzados (19 milhões já comprometidos com pagamento de funcionários), correspondente a $0,034 \%$ do orçamento estadual. Nesse momento, há uma tendência da equipe em criar uma fundação para a cultura ${ }^{22}$, projeto que não se concretizou posteriormente.

As tensões e o diálogo entre o campo artístico e a política, potencializado a partir do movimento das Diretas Já, é documentado em reportagens às vésperas da Constituinte, ecoando propostas dos artistas articulados pela Associação Chico Lisboa, Clube de Cultura e Movimento Gaúcho pela Constituinte. Em pleno processo de redemocratização, nota-se a predisposição de segmentos artísticos em influir no novo espaço público que se desenhava no período, pontuada por vozes sempre céticas e realistas como a do pintor Iberê Camargo: “[...] Os políticos só falam e procuram votos" 23 . Ao cobrir a greve geral convocada pelas centrais sindicais em 12 de dezembro de 1986, o jornal repercutiu em matéria de capa o ponto de vista dos artistas sobre o episódio, sinalizando a importância da cultura na cobertura geral do periódico ${ }^{24}$.

A Lei Sarney de 1986, que transferiu parte do financiamento da produção artística para decisão da esfera privada, também repercutiu no setor, ainda que seu uso, no período estudado, fosse incipiente e levantasse muitas dúvidas entre os produtores. A editoria esteve atenta para a relação entre empresas e a cultura, valorizando projetos e casos de marketing ${ }^{25}$, processo esse sintonizado com a tendência internacional da promoção da produção artística com capital privado a partir da década de 1980 (Wu, 2006).

\section{Considerações finais}

Cada publicação produz uma perspectiva sobre a realidade, carrega consigo uma proposta editorial de cultura, respondendo às contingências de produção do discurso jornalístico. Nesse processo, estabelece parâmetros para aferir a vida cultural e artística de uma comunidade, cumprindo uma função formativa no horizonte de percepção do público. Esta análise percorreu os parâmetros propostos pelo jornal Diário do Sul, que constituiu um capítulo diferenciado na história da imprensa no Rio Grande do Sul ao defender o jornalismo diário analítico, seguindo a linha editorial da Gazeta Mercantil e o ideário dos quality-papers. Ao entender a arte e a cultura como formas privilegiadas de conhecimento do mundo, construiu a notícia por meio de critérios como memória, contexto e valor econômico.

Na sua condição de intermediário, o jornal percorreu as diversas instâncias do sistema cultural, registrando os movimentos das áreas de criação, difusão, preservação, análise e consumo. A editoria de cultura do DS não fugiu do cânone consensual, enfatizou os expoentes do campo, a agenda de eventos, a temporalidade do produto, mas foi bastante sensível aos processos culturais, opção rara dentro do jornalismo cultural. Os dados obtidos demonstraram a ênfase na economia da cultura, ilustrando-a com informações que permitem avaliar o quanto uma conjuntura recessiva - marcada pela alternância de projetos como o Plano Cruzado, Plano Cruzado II e Plano Bresser -, interferiu ora na expansão, ora na retração das atividades e da infraestrutura do setor cultural em Porto Alegre entre 1986 e 1988. Em geral, as lógicas de interesse econômico das práticas culturais e artísticas são pouco discutidas; também não se costuma avaliar o impacto e a importância que o setor cultural alcança na atividade econômica. Como foi dito anteriormente, na maioria das vezes, a cobertura jornalística reproduz a economia da cultura por meio da lógica da oferta (oferecimento dos diversos produtos) e na amplificação de determinados valores deste campo como o sujeito criador, estilo e assinatura.

Destacaram-se, também, na análise realizada, os registros minuciosos sobre a institucionalização da cultura no Estado, permitindo encontrar a gênese e a estruturação de diferentes pólos gerenciadores que permanecem em vigor até o momento. Enfim, ao sondar a economia do setor, assim como a articulação política do segmento, o jornalismo produzido na experiência do Diário do Sul ofereceu possibilidades alternativas de abordar o movimento, a memória e a transformação do sistema cultural de Porto Alegre em meados da década de 1980 FAMECOS

\section{NOTAS}

* Esta é uma versão revisada e ampliada do paper homônimo que foi apresentado no $7^{\circ}$ Encontro Nacional de Pesquisadores em Jornalismo, 2009, São Paulo.

1 Pesquisa realizada no LEAD/FABICO/UFRGS com recursos da UFRGS, FAPERGS e CNPq. Participam da investigação o Mestre em Comunicação Everton Cardoso e a Mestranda PPGCOM UFRGS Ana Laura Colombo de Freitas. Entre 2008 e 2009 trabalharam as bolsistas BIC-FAPERGS Sara Keller e Priscila Musykant, BIC/UFRGS Samantha Klein, Bruna Menezes e Rafael Glória, além do bolsista voluntário PROPESQ Tales Gubes Vaz; em 2007 foram bolsistas BIC-UFRGS Flávia Moraes e BIC-FAPERGS 
Raquel Hirai.

2 Cf. Bardin (2004) e Bauer (2002).

3 Cf. Meihy (1996), Thompson (1992).

4 Entre 1985 e 1986, a Gazetinha estava com aproximadamente 15 mil assinantes, São Paulo 20 mil e Rio de Janeiro 12 mil (Gama, 2008).

5 Detalhamento sobre a concepção do jornal e seus processos editoriais estão disponíveis em GOLIN, Cida; GRUSZYNSKI, Ana. Cultura e processos editoriais: a representação do sistema artístico-cultural no Diário do Sul (1986-1988). In: Anais do XXXII Congresso Brasileiro de Ciências da Comunicação. Curitiba: INTERCOM, 2009.

6 Trata-se de um modelo de negócio apoiado na racionalização de custos e maximização de lucros, estruturado como conglomerado de mídias (televisão, jornal e rádio) em uma região de interesse: Rio Grande do Sul e Santa Catarina.

7 Entrevista, documento não paginado.

8 A tiragem diária era publicada na capa do jornal.

9 A amostra quantificou três meses alternados do primeiro semestre de existência do jornal (novembro 1986, janeiro e março de 1987) e três meses do último (maio, julho e setembro de 1988). Aplicou-se uma tabela para indexação e tabulação de 1.469 matérias em cerca de 150 edições. Os dados podem ser conferidos em GOLIN, Cida; GRUSZYNSKI, Ana Cláudia; CARDOSO, Everton Terres; KELLERS, Sara; VAZ, Tales. Cultura na primeira página: o jornal Diário do Sul e a representação do sistema artístico-cultural. In: Anais do $6^{\circ}$ Encontro Nacional de Pesquisadores em Jornalismo. São Bernardo do Campo: SBPJor, 2008.

10 A análise qualitativa identificou em cada texto da amostra os seguintes pontos: título, autor, detalhamento da identidade das fontes, critérios para seleção das pautas, critérios de edição; perspectiva, temporalidade, detalhamento da tipografia, imagem e ilustração. O conjunto de cada semana foi compilado em torno dos eixos descritivos: conceito de cultura, público previsto, identidade das fontes, critérios de edição e seleção de pauta e retrato do sistema artístico e cultural.

11 Relatório: Investimento em Arte, publicado em 17 nov. 1986.

12 "Em discussão, a crise da linguagem" de L. C. Barbosa, 26 jul.1988, contracapa Cultura e Lazer.

13 "A busca de produtores especializados" de L.C. Barbosa, 26 jul 1988, contracapa Cultura e Lazer.

14 "A Fonte, maturidade que marca um novo momento", de A. Hohlfeldt, 19 mai.1988, p.16.

15 Dados do Sindicato Nacional dos Editores de Livros em "Criança, um filão consolidado", de A.B.Pinto, 05 nov. 1986.

16 Os sobreviventes de Fuller, de L.C. Merten, 04 nov. 1986, p.8.

17 Relatório: Jovens, publicado em 14 nov. 1986.
18 Relatório: Vídeo, 24 dez. 1986.

19 "Enfim, o Araújo Vianna reaberto para a música", de R.L. Dalto, 06 jan. 1987, p.7 e "Festivais de espetáculos reabre o Salão de Atos", de S. Ferreira, em 27 jul.1988, p.1A.

20 Registra-se ainda na amostra qualitativa a primeira fase de restauração do Museu do Trabalho e a abertura da casa de espetáculos Átrio.

21 "Faltam recursos para aprovados pela Ospa", de S. Ferreira, 26 jul. 1988, contracapa caderno Cultura e Lazer.

22 "Governo Simon estrutura o novo conselho cultural", de R. L. Dalto, 18 mar. 1987, p.12.

23 "Os artistas e a Constituinte", de L. C. Barbosa, 16 mar. 1987, capa.

24 "Solidariedade dos artistas", L. C. Barbosa, 12 dez. 1986, capa.

25 "Projeto para preservar o patrimônio artístico" e "Atlantic e Atlântida FM levam público às salas", de Cléa Motti, 25 jul. 1988, capa Cultura e Lazer.

\section{REFERÊNCIAS}

BARDIN, Laurence. Análise de conteúdo. Lisboa: Edições 70, 2004.

BARBOSA, L. C. [Entrevista]. Entrevista concedida ao grupo de pesquisa do Laboratório Eletrônico de Arte $\mathcal{E}$ Design da Faculdade de Biblioteconomia e Comunicação da Universidade Federal do Rio Grande do Sul em Porto Alegre, 24 nov. 2008.

BAUER, Martin. Análise de conteúdo clássica: uma revisão. In: BAUER, Martin; GASKELL, George. Pesquisa qualitativa com texto, imagem e som: um manual prático. Petrópolis, RJ: Vozes, 2002.

BENHAMOU, Françoise. A economia da cultura. Cotia, SP: Ateliê Editorial, 2007.

BRITTES, Blanca. Breve olhar sobre os anos oitenta. In: GOMES, Paulo (Org.) Artes plásticas no Rio Grande do Sul: uma panorâmica. Porto Alegre: Lahtu Sensu, 2007, p. 136-155.

CHLOË, Salles. Covering the internet: an acculturation strategy for press of record? The Academic track of IJ-6. In: Sixth Conference on Innovation Journalism. May, 2009, Stanford. Disponível em: <http://www.innovationjournalism.org/ij6ac/ papers/1994/05/covering-internet-acculturation. html>. Acesso em: 17 jul. 2009.

CONNELL, Ian. Mistaken identities: tabloid and broadsheet news discourse. The Public, v.5 n.3, 1998. Disponível em: <http://www.javnostthepublic.org/media/datoteke/1998-3-connel. pdf >. Acesso em: 17 jul. 2009. 
CUNHA, Leonardo; FERREIRA, Nísia;

MAGALHÃES, Luís. Dilemas do jornalismo cultural brasileiro. Temas: Ensaios de Comunicação, v.1, n.1, 2002.

DIAS, Márcia. Os donos da voz. Indústria fonográfica e mundialização da cultura. São Paulo: Boitempo, 2008.

FONSECA, Virginia. Indústria de notícias. Capitalismo e novas tecnologias no jornalismo contemporâneo. Porto Alegre: Editora da UFRGS, 2008.

GAMA, H. [Entrevista]. Entrevista concedida ao grupo de pesquisa do Laboratório Eletrônico de Arte $\mathcal{E}$ Design da Faculdade de Biblioteconomia e Comunicação da Universidade Federal do Rio Grande do Sul em Porto Alegre, 08 dez. 2008.

JANUÁRIO, Marcelo. O olhar superficial: as transformações do jornalismo cultural em São Paulo na passagem para o século XXI. São Paulo, SP. Dissertação de Mestrado. Universidade de São Paulo, 2005.

LENE, Hérica. A crise da Gazeta Mercantil: tradição e ruptura no jornalismo econômico brasileiro. 2004. Dissertação (Mestrado) - Universidade Federal Fluminense, 2004.

MALOVIC, Stjepan; VILOVIC, Gordana. Tabloidization Conquers Quality Press. Disponível em: <http://soemz.euvfrankfurt-o.de/media-see/qpress/articles/ sm_gv.html>. Acesso em: 17 jul. 2009.

MANUAL DE REDAÇÃO. Porto Alegre: Diário do Sul, s/d.

MARINI, Ana Rita Sant'anna. Diário do Sul: breve trajetória de um jornal porto-alegrense com espírito cosmopolita. 2002. Monografia (Graduação em Jornalismo) - Universidade do Vale do Rio dos Sinos, 2002.

MEIHY, José. Manual de história oral. São Paulo: Ed. Loyola, 1996.

ORTIZ, Renato. A moderna tradição brasileira. São Paulo: Brasiliense, 1988.

ROZADOS, Helen [Entrevista]. Entrevista concedida ao grupo de pesquisa do Laboratório Eletrônico de Arte $\mathcal{E}$ Design da Faculdade de Biblioteconomia e Comunicação da Universidade Federal do Rio Grande do Sul em Porto Alegre, 29 abr. 2009.
RÜDIGER, Francisco. Tendências do jornalismo. Porto Alegre: Editora da UFRGS, 2003.

SIMIS, Anita. Cinema e política cinematográfica. In: BOLAÑO, C.; GOLIN, C.; BRITTOS, V. (Orgs). Economia da arte e da cultura. (coletânea inédita), 2009.

TOLILA, Paul. Cultura e economia: problemas, hipóteses, pistas. São Paulo: Iluminuras/Itaú Cultural, 2007.

THOMPSON, Paul. A voz do passado: história oral. Rio de Janeiro: Paz e Terra, 1992.

TUBAU, Iván. Teoria y pratica del periodismo cultural. Barcelona: ATE/Fontes, 1982.

URBIM, C. [Entrevista]. Entrevista concedida ao grupo de pesquisa do Laboratório Eletrônico de Arte $\mathcal{E}$ Design da Faculdade de Biblioteconomia e Comunicação da Universidade Federal do Rio Grande do Sul em Porto Alegre, 17 jun. 2009.

WEISS, J. [Entrevista]. Entrevista concedida ao grupo de pesquisa do Laboratório Eletrônico de Arte $\mathcal{E}$ Design da Faculdade de Biblioteconomia e Comunicação da Universidade Federal do Rio Grande do Sul em Porto Alegre, 20 mai. 2009

WILLIAMS, Raymond. Cultura. São Paulo: Paz e Terra, 2000.

WU, Chin-Tao. Privatização da cultura: a intervenção corporativa na arte desde os anos 1980. São Paulo: Boitempo, 2006. 